\title{
Evaluation of Fluorescent Analogs of Deoxycytidine for Monitoring DNA Transitions from Duplex to Functional Structures
}

\author{
Yogini P. Bhavsar, Samantha M. Reilly, and Randy M. Wadkins \\ Department of Chemistry and Biochemistry, The University of Mississippi, Coulter Hall, Room 409, MS 38677, USA
}

Correspondence should be addressed to Randy M. Wadkins, rwadkins@olemiss.edu

Received 15 May 2011; Accepted 19 June 2011

Academic Editor: F. C. Simmel

Copyright ( $) 2011$ Yogini P. Bhavsar et al. This is an open access article distributed under the Creative Commons Attribution License, which permits unrestricted use, distribution, and reproduction in any medium, provided the original work is properly cited.

\begin{abstract}
Topological variants of single-strand DNA (ssDNA) structures, referred to as "functional DNA," have been detected in regulatory regions of many genes and are thought to affect gene expression. Two fluorescent analogs of deoxycytidine, Pyrrolo-dC (PdC) and 1,3-diaza-2-oxophenoxazine $\left(\mathrm{tC}^{\circ}\right)$, can be incorporated into DNA. Here, we describe spectroscopic studies of both analogs to determine fluorescent properties that report on structural transitions from double-strand DNA (dsDNA) to ssDNA, a common pathway in the transition to functional DNA structures. We obtained fluorescence-detected circular dichroism (FDCD) spectra, steady-state fluorescence spectra, and fluorescence lifetimes of the fluorophores in DNA. Our results show that PdC is advantageous in fluorescence lifetime studies because of a distinct $\sim 2 \mathrm{~ns}$ change between paired and unpaired bases. However, $\mathrm{tC}^{\circ}$ is a better probe for FDCD experiments that report on the helical structure of DNA surrounding the fluorophore. Both fluorophores provide complementary data to measure DNA structural transitions.
\end{abstract}

\section{Introduction}

DNA single strands can hybridize to form higher-order functional structures, which include hairpins, triplexes, and quadruplexes [1-4]. The existence and physiological relevance of these secondary structures in vivo have been the subject of much controversy. However, several in vivo techniques have confirmed the presence of DNA secondary structures in telomeres and regulatory regions of specific genes (e.g., BCL-2, c-myc) [5-8]. Secondary structures may also serve as specific targets recognized by drugs, such as actinomycin D and PIPER, as well as transcription factors, such as Sp1, because of their topological variance from duplex Watson-Crick DNA $[9,10]$.

On account of their occurrence in regulatory regions and their structural peculiarity, functional DNA structures may serve as biological microswitches for altering transcription by silencing or enhancing gene expression [11, 12]. Exercising control over gene expression by controlling the activation of these switches and/or introducing new switches in biological circuits could revolutionize medical research and offer new avenues of treating genetic disorders. For exercising such control, it is imperative to understand the factors affecting the mechanism of formation and maintenance of functional structures at a fundamental level.

Numerous fluorescent analogs of DNA bases have been evaluated for examining the subtleties of DNA transitions [13-15]. Locating an appropriate probe that could map the mechanistic aspects of transition of double stranded (ds) DNA to single stranded (ss) secondary structure is a first step toward monitoring the formation of complex, higher-order structures since ssDNA is an intermediate in the pathway to functional structures. In the following report, we present a comparative study of two deoxycytidine analogs, PdC and $\mathrm{tC}^{\circ}$ (Figure 1), to evaluate their suitability as fluorescent reporter probes for DNA transitions.

The properties of pyrrolocytosine and the effects of base stacking and hydrogen bonding on its quantum yield in nucleic acids have been previously evaluated [16]. Based on this prior work, we reported the use of $\mathrm{PdC}$ to determine 


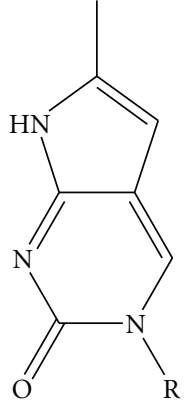

PdC<smiles>[R]n1cc2c(nc1=O)Nc1ccccc1O2</smiles>

$\mathrm{tC}^{\circ}$
Figure 1: Structures of $\mathrm{PdC}$ and $\mathrm{tC}^{\circ}$. $\mathrm{R}$ indicates the linkage to deoxyribose.

hairpin formation in short oligos (16 nucleotides) [17]. The fluorophore was stable in these oligos and did not perturb DNA structure. This result implied that PdC might be a useful probe for investigating more complex DNA functional structures in detail. However, to overcome certain limitations of PdC, we also explored another recently characterized fluorescent base analog, $\mathrm{tC}^{\circ}$.

The $\mathrm{tC}^{\circ}$ has a quantum yield five-times greater than $\mathrm{PdC}$ $\left(\mathrm{Q}_{\mathrm{f}}=0.30\right.$ for $\left.\mathrm{tC}^{\circ}\right)$ and a molar absorptivity maximum of $9000 \mathrm{M}^{-1} \mathrm{~cm}^{-1}$ at $360 \mathrm{~nm}$ [18]. The absorbance wavelength of $\mathrm{tC}^{\circ}$ is similar to $\mathrm{PdC}$, which allows both to be easily distinguishable from DNA. Both of these fluorophores have been reported to be quenched, relative to the single strand, when base-paired with guanine, making it easy to determine when the DNA is in the duplex form $[17,19]$. In addition, unlike $\mathrm{PdC}, \mathrm{tC}^{\circ}$ has only minor variations in fluorescent properties caused by surrounding bases [20]. However, like $\mathrm{PdC}, \mathrm{tC}^{\circ}$ induces little or no changes in stability upon incorporation into dsDNA. High quantum yield, retention of the original configuration of DNA, and quenching when base-paired suggested that $\mathrm{tC}^{\circ}$ would be a useful fluorescent probe for mapping the transition of duplex DNA to a functional DNA structure spectroscopically. In this paper, we compare spectral properties of $\mathrm{tC}^{\circ}$ and $\mathrm{PdC}$ for use as reporters of DNA conformation. The DNA sequence used (Table 1) is known to form a cruciform structure in the cloning vector pBR322 under superhelical duress [21, 22]. This sequence was chosen since the results from the work described here will provide a context for interpreting data in future studies of the $\mathrm{PdC}$ and $\mathrm{tC}^{\circ}$ incorporated into this supercoiled plasmid. Hence the effect of supercoiling on functional structure formation and conformation can be potentially probed with these fluorescent bases.

\section{Materials and Methods}

2.1. Materials and Equipment. All DNA oligonucleotides (sequences shown in Table 1), including those incorporating $\mathrm{PdC}$ and $\mathrm{tC}^{\circ}$, were obtained from Midland Certified Reagent Co. (Midland, TX, USA). All oligos were dissolved in
TABLE 1: The 113-mer DNA sequence that is part of the cruciform found in the terminator of the Amp ${ }^{\mathrm{R}}$ cassette in the cloning vector pBR322 under superhelical strain. The location of the substitution of cytidine by the fluorescent analogs marked by an asterisk.

\begin{tabular}{l}
\hline Sequence \\
\hline 5'-TGA GGT TAA GGG ATT TTG GTC ATG AGA TTA TCA AAA \\
AGG ATC TTC* ACC TAG ATC CTT TTA ATT AAA AAT GAA \\
GTT TTA AAT CAA TCT AAA GTA TAT ATG AGT AAA CTT \\
GGG C - $3^{\prime}$
\end{tabular}

TE buffer (10 mM Tris, $1 \mathrm{mM}$ EDTA, $\mathrm{pH}$ 8) made from spectroscopic-grade reagents obtained from Fisher Scientific. Purity of each oligo was assessed using agarose gels, which showed no other higher or lower molecular weight contaminations. CD and FDCD experiments were performed using a circular dichroism instrument (Model 202SF, AVIV Biomedical Inc. Lakewood, NJ, USA) and fluorescence lifetime measurements were conducted on a multifrequency cross-correlation phase and modulation fluorometer (model K2, ISS Inc., Champaign, IL, USA).

2.2. Duplex Oligos. After ensuring the purity of the singlestrand $\mathrm{PdC}, \mathrm{tC}^{\circ}$, and wildtype ( $\mathrm{ssPdC}$, sst $\mathrm{C}^{\circ}$, and ssWT; the WT contains no fluorophore) oligos, each was mixed with a slight molar excess of their complementary strand. This was heated to $80^{\circ} \mathrm{C}$ for 20 minutes, and then cooled to room temperature to anneal strands. The double-strand oligo formation was confirmed by observing the difference in migration of ds- and ss-oligos on agarose gels and compared to a DNA ladder of the known length. In addition, duplex was the only strand observed after staining with the SYBR Gold, which stains both ss- and dsDNA.

2.3. CD and UV Absorbance. CD spectra were recorded using a quartz cuvette having an optical path length of $1 \mathrm{~cm}$. All oligos analyzed were in $700 \mu \mathrm{L}$ volume at concentration of $0.35 \mu \mathrm{M}$. Wild-type oligos were analyzed to ensure that the signals were not modified by the fluorophores. Each data point was averaged over an integration time of $1 \mathrm{~s}$ per $\mathrm{nm}$. $\mathrm{CD}$ signals were collected from $25^{\circ} \mathrm{C}$ to $90^{\circ} \mathrm{C}$ over the range of $220 \mathrm{~nm}$ to $420 \mathrm{~nm}$ to check for any change in the global conformation of the single-stranded and double-stranded WT, $\mathrm{PdC}$, and $\mathrm{tC}^{\circ}$ oligos. While performing $\mathrm{CD}$ scans, the total UV absorbance of each oligo was also collected.

2.4. FDCD. FDCD spectra were collected using a quartz cuvette of $1 \mathrm{~cm}$ path length. Oligos analyzed were in a total volume of $70 \mu \mathrm{L}$ and at the concentration of $8.5 \mu \mathrm{M}$. Each FDCD scan was averaged over 15 seconds per $\mathrm{nm}$ in order to increase signal-to-noise ratio. The excitation wavelengths were from $300 \mathrm{~nm}$ to $420 \mathrm{~nm}$ at temperatures ranging from $25^{\circ} \mathrm{C}$ to $90^{\circ} \mathrm{C}$. Emission was obtained by using a $450 \mathrm{~nm}$ cuton filter.

2.5. Steady-State Fluorescence. Steady-state fluorescence spectra were analyzed for ss- and ds- (WT, $\mathrm{PdC}$, and $\mathrm{tC}^{\circ}$ ) oligos. All the oligos had concentration of $0.35 \mu \mathrm{M}$ in $\mathrm{TE}$ 


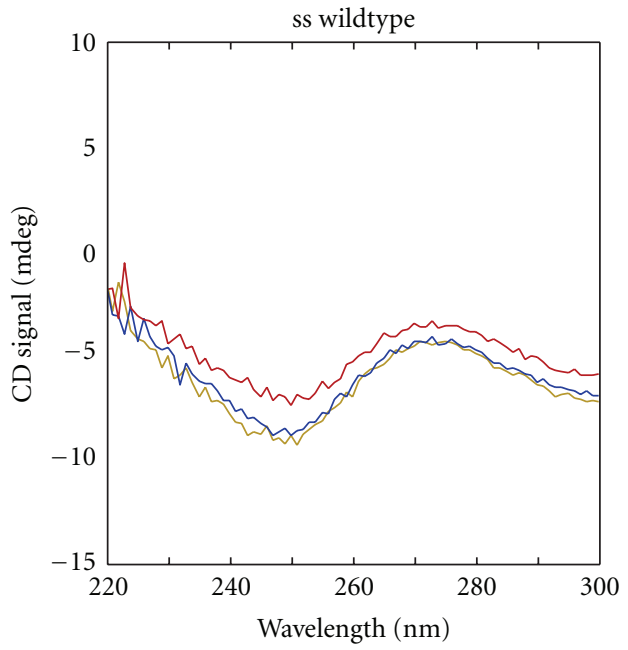

(a)

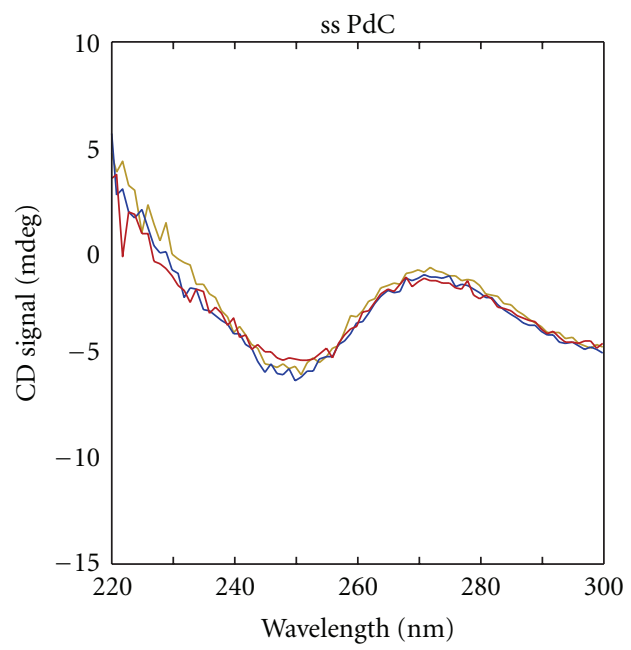

(c)

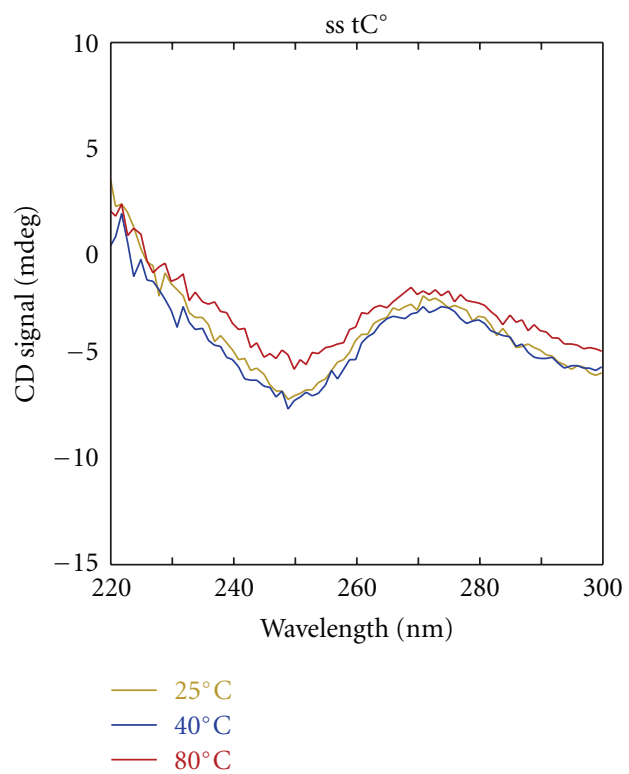

(e)

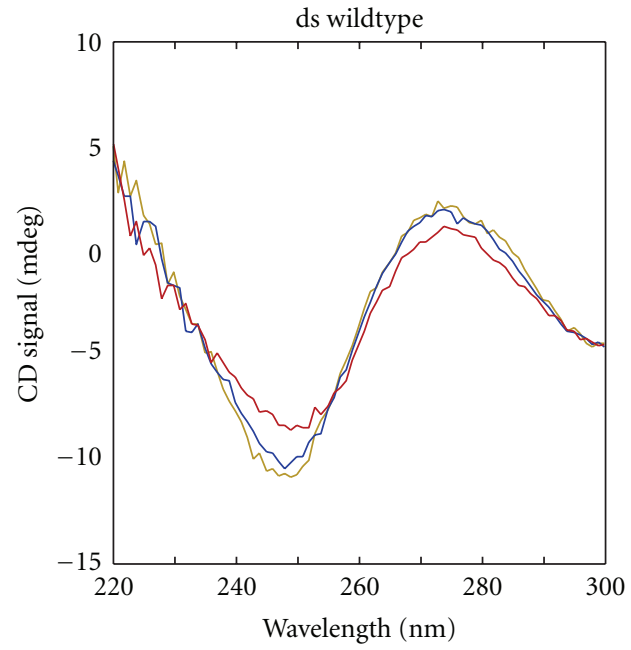

(b)

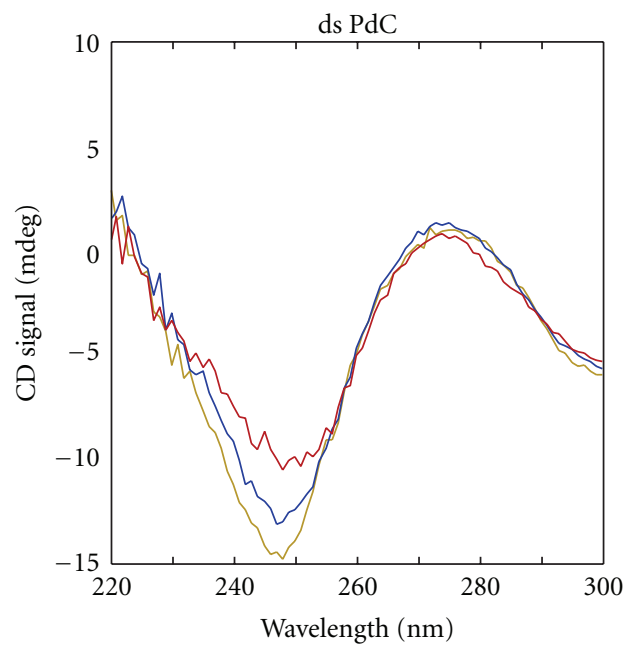

(d)

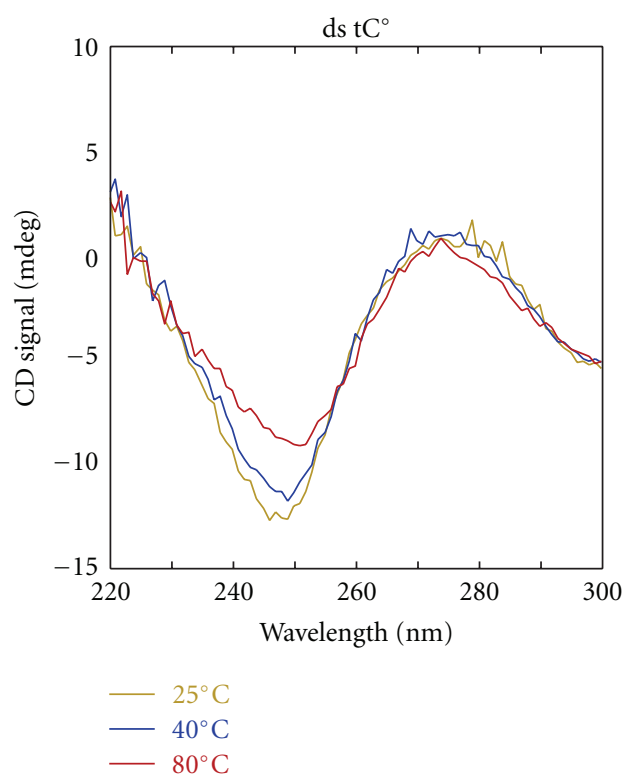

(f)

Figure 2: The characteristic CD spectrum of wild type ss- and ds-oligos as a function of temperature. All samples were at $0.35 \mu \mathrm{M}$ concentration. 
TABle 2: Fluorescence lifetimes of $\mathrm{PdC}$ and $\mathrm{tC}^{\circ}$ in single- and double-strand DNA. The $\tau_{1}$ and $\tau_{2}$ are obtained by fitting a double exponential decay curve to the data, and $f_{1}$ and $f_{2}$ are fraction of fluorescence corresponding to lifetimes $\tau_{1}$ and $\tau_{2}$, respectively. The $\chi^{2}$ indicate the measure of error in the fit. The value $\langle\tau\rangle$ is average lifetime calculated by $\sum f_{i} \tau_{i}^{2} / \sum f_{i} \tau_{i}$.

\begin{tabular}{lcccccc}
\hline Oligo & $\tau_{1}(\mathrm{~ns})$ & $f_{1}$ & $\tau_{2}(\mathrm{~ns})$ & $f_{2}$ & $\chi^{2}$ & $\langle\tau\rangle(\mathrm{ns})$ \\
\hline ss tC $^{\circ}$ & 5.3 & 0.9 & 1.7 & 0.1 & 2.0 & 5.1 \\
ds tC & 5.1 & 0.8 & 1.8 & 0.2 & 1.5 & 4.8 \\
ss PdC & 5.2 & 0.7 & 0.7 & 0.3 & 1.9 & 5.1 \\
ds PdC & 3.3 & 0.6 & 0.1 & 0.3 & 1.4 & 3.2 \\
\hline
\end{tabular}

buffer (10 mM Tris, $1 \mathrm{mM}$ EDTA, pH 8). Excitation scans were collected over the wavelength range of $220-400 \mathrm{~nm}$, with the emission wavelength fixed at $450 \mathrm{~nm}$. Emission spectra were taken over the wavelength ranging from $400 \mathrm{~nm}$ to $580 \mathrm{~nm}$ with the excitation wavelength fixed at $350 \mathrm{~nm}$. The ss- and dsWT oligos were used as a baseline signal and subtracted from the steady-state fluorescence data.

2.6. Fluorescence Lifetime Measurements. Fluorescence lifetime was measured for both ss- and ds-oligos using a frequency domain lifetime instrument. The cuvettes used were of $1 \mathrm{~cm}$ path length. Excitation wavelengths were $350 \mathrm{~nm}$ and $368 \mathrm{~nm}$ for $\mathrm{PdC}$ and $\mathrm{tC}^{\circ}$, respectively. Data were collected from $10-240 \mathrm{MHz}$ frequencies with 100 iterations at each frequency and 40 total frequencies from which the lifetimes were calculated. Both the individual decays (fitted to 2 components) and average lifetimes are reported.

\section{Results and Discussion}

3.1. Incorporation of Fluorescent DC Analogs Does Not Perturb DNA Structure. In order to assure that no structural perturbations were introduced by insertion of the fluorophores in the oligos, changes in absorbance at $260 \mathrm{~nm}$ were monitored at varying temperatures to determine duplex melting temperatures as well as any transitions occurring in ssDNA (data not shown). The data indicated that the ssWT, ssPdC, and $\mathrm{sstC}^{\circ}$ undergo similar spectral changes with temperature, indicating no perturbations to the ssstructures after replacement of cytidine with $\mathrm{PdC}$ or $\mathrm{tC}^{\circ}$. The absorbance for all ssDNA increases by $\sim 10 \%$ from $25^{\circ} \mathrm{C}$ to $40^{\circ} \mathrm{C}$, signifying reorientation of the strands during melting. Thus, introduction of either $\mathrm{PdC}$ or $\mathrm{tC}^{\circ}$ did not lead to the formation of any additional secondary conformation in ssoligos as predicted based on the previous literature $[17,19]$.

No perturbation of dsDNA by $\mathrm{PdC}$ or $\mathrm{tC}^{\circ}$ was observed. All duplexes melted at $45 \pm 3^{\circ} \mathrm{C}$ in TE buffer. This indicated dsDNA containing the fluorescent bases were readily formed and stable at $25^{\circ} \mathrm{C}$. Hence, $\mathrm{PdC}$ and/or $\mathrm{tC}^{\circ}$ could be used to investigate single- and double-stranded regions of DNA functional structures.

Circular dichroism (CD) spectroscopy was also used to investigate whether the overall helical structural conformation of the DNA might have been affected by the fluorophores (Figure 2). Our results, in agreement with melting data from absorbance and the literature, indicated that the fluorophores did not affect the structure of the duplexes or the manner in which they melted [17, 23, 24]. There were only negligibly small changes in the CD spectrum with temperature for ss-oligos, which indicated little structure at any temperature as compared to dsDNA. The dsDNA oligos showed considerable CD, consistent with the common global spectral features typical of B-DNA [25]. Major changes in the $\mathrm{CD}$ signal of dsDNA with respect to the temperature were observed at $245 \mathrm{~nm}$, with relatively smaller changes that occurred at $280 \mathrm{~nm}$. These CD spectra and their temperature dependence illustrated that the DNA is not affected by replacing cytidine with $\mathrm{PdC}$ or $\mathrm{tC}^{\circ}$.

\subsection{The Local Helical Structure of DNA Can Be Probed by} Induced FDCD of $t C^{\circ}$. Circular dichroism has been used for detecting the local environmental changes around $\mathrm{PdC}$ integrated into DNA [26]. However, the direct detection of $\mathrm{CD}$ by $\mathrm{PdC}$ or other base analogs is restricted to analogs that either have an absorbance far enough removed from the DNA $\lambda_{\max }$ of $260 \mathrm{~nm}$ to prevent spectral overlap or are incorporated into short DNA sequences. In both cases, significant amounts of DNA are required to obtain good signal-to-noise. An alternative approach to direct CD observation is to use FDCD to study the local environment of the fluorescent base analog. Since our previous data has sufficiently demonstrated that the replacement of deoxycytidine with either $\mathrm{PdC}$ or $\mathrm{tC}^{\circ}$ does not affect the original DNA structure, we analyzed the fluorophores by FDCD to explore the local structural changes occurring around the base. In our studies, PdCcontaining DNA at concentrations up to $8.5 \mu \mathrm{M}$ did not show any FDCD signal over the temperature range of $25^{\circ} \mathrm{C}$ to $90^{\circ} \mathrm{C}$, suggesting that PdC's low quantum yield is insufficient for FDCD measurements at reasonable DNA concentrations with our instrument. However, $\mathrm{tC}^{\circ}$ showed a strong FDCD signal for both ss- and dsDNA between $300 \mathrm{~nm}$ and $420 \mathrm{~nm}$ even at submicromolar concentrations $(0.5 \mu \mathrm{M}$; Figure 3$)$. The FDCD signal for duplex DNA was significantly larger than that for the ss oligo. In addition it had a positive value throughout, indicating the base was stacked parallel to the bases in the vicinity. The lower intensity of the peak in ss-oligos is attributed to the residual structure at room temperature. Thus, $\mathrm{tC}^{\circ}$ is a very effective probe for monitoring the localized changes occurring in DNA structure in response to variations in structural parameters.

FDCD data obtained can be used for predicting the molecular details of higher-order secondary structures. For example, in case of loop regions of i-motif and cruciform structures, $\mathrm{tC}^{\circ}$ will exhibit lower FDCD signal since these regions are less structured. However, $\mathrm{tC}^{\circ}$ substituting for $\mathrm{dC}$ in the regions where base-pairing occurs should show higher FDCD signals. These structural details could then be used to assess the stabilities of functional DNA structures after binding of transcription factors or drugs.

3.3. Fluorescence Properties of the Base Analogs Reveal Their Pairing State. Fluorescence intensities of $\mathrm{PdC}$ and $\mathrm{tC}^{\circ}$ depend on their hydrogen bonding state, and decrease if the 


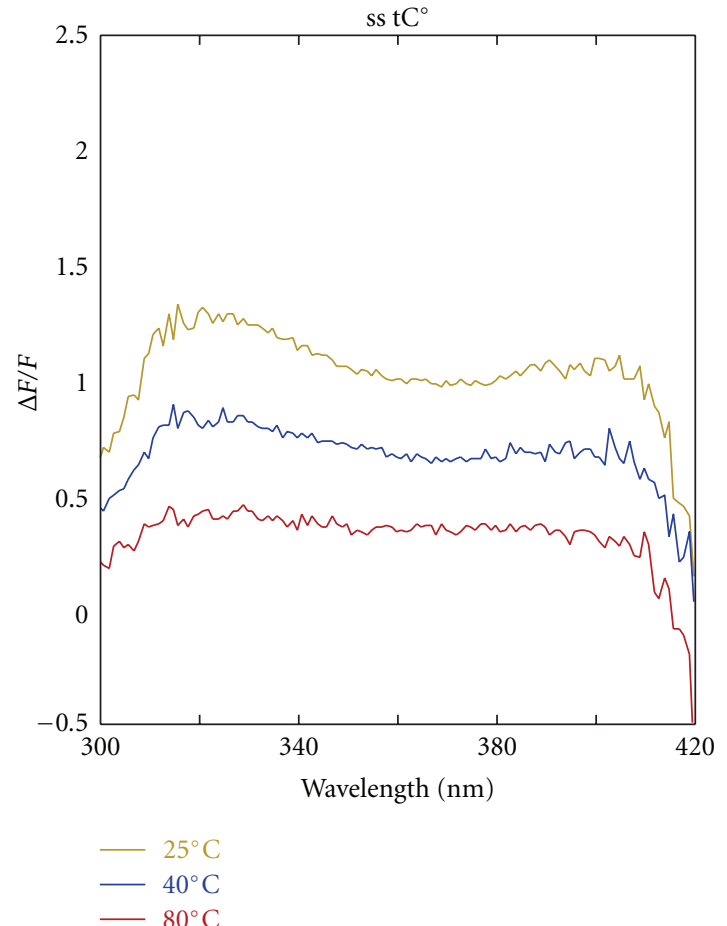

(a)

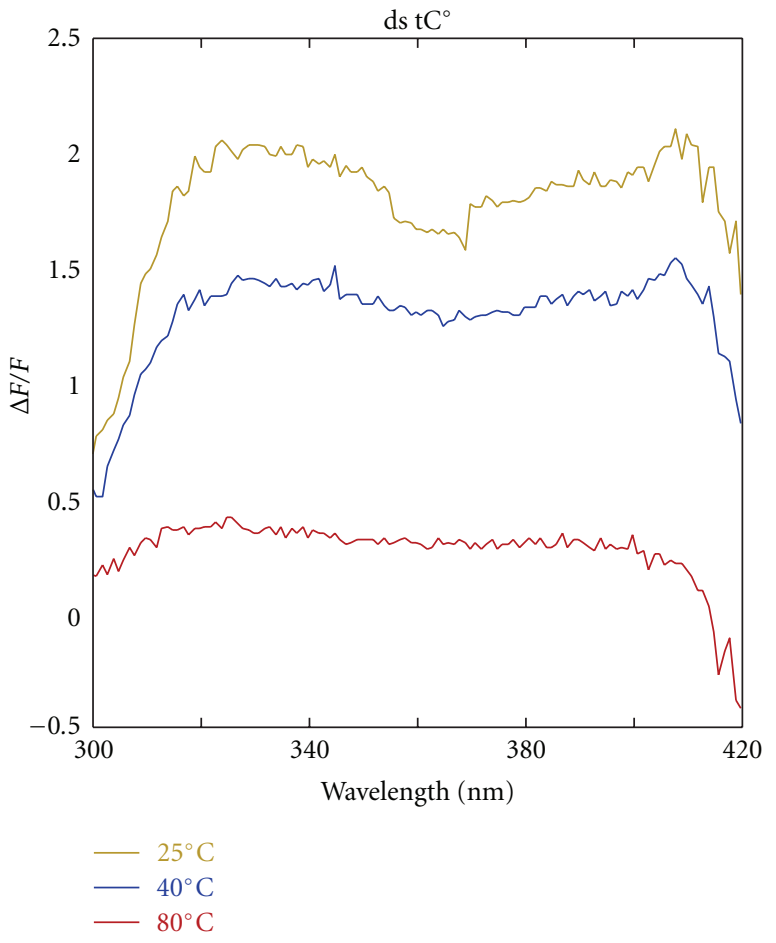

(b)

Figure 3: FDCD spectra with respect to temperature for PdC and $\mathrm{tC}^{\circ}$. The low quantum yield of PdC did not allow for detection of FDCD at this concentration. $\triangle F / F$ is the difference in the fluorescence caused by left- and right-handed polarized light over total fluorescence of the fluorophore.

fluorophores are base-paired [17, 19]. Figure 4 clearly demonstrate this quenching of fluorescence for both PdC and $\mathrm{tC}^{\circ}$ in duplex dsDNA versus unpaired ssDNA. Fluorescence intensities from ssDNA to dsDNA are lowered by approximately $60 \%$ and $40 \%$ for $\mathrm{PdC}$ and $\mathrm{tC}^{\circ}$, respectively. Figure 4 also shows the difference in the quantum yield of $\mathrm{PdC}$ and $\mathrm{tC}^{\circ}$, with $\mathrm{PdC}$ exhibiting significantly lower fluorescence. Both the fluorophores had an excitation maximum at $350 \mathrm{~nm}$ and an emission maximum of $450 \mathrm{~nm}$ that did not change in ssDNA versus dsDNA. These decreases in the fluorescence and the location of the maxima are consistent with the known literature $[8,19]$.

Like steady-state intensities, fluorescence lifetimes of PdC and $\mathrm{tC}^{\circ}$ decrease when they are paired to their complementary base $[17,19]$. Since fluorescence lifetimes are independent of concentration, their decrease has the potential to be used for differentiating paired bases from unpaired, thus they can be used for deductively mapping functional DNA structures. Lifetime data was obtained at room temperature for both ss- and ds-oligos. Two lifetimes $\left(\tau_{1}, \tau_{2}\right)$ were fit to the phase-modulation data. The weighted average of the two lifetimes, $\tau_{1}$ and $\tau_{2}$, were calculated and reported as $\langle\tau\rangle$ in Table 2. These weighted averages indicate that the lifetimes for $\mathrm{tC}^{\circ}$ decreased slightly ( $0.3 \mathrm{~ns}$ ) with respect to the strandedness. In contrast, $\mathrm{PdC}$ showed appreciable difference (1.9 ns) between single and duplex oligos. These lifetime values are similar to those previously reported $[17,19]$. To unambiguously differentiate between the ss- and ds regions of the secondary structures, greater differences in lifetimes of base-paired and unpaired fluorophores are required. Thus, the lifetime data indicates that $\mathrm{PdC}$ is a better choice than $\mathrm{tC}^{\circ}$ for assessing the strand base-pairing in DNA via this methodology. Similar to FDCD, lifetime measurements can facilitate the studies to observe differences between ss loop regions and ds regions in functional DNA structures like imotif and cruciforms, and hence aid the studies to investigate formation and stability of secondary structures.

\section{Conclusions}

In this report, spectroscopic techniques were used to determine the appropriate fluorescent deoxycytidine analog for probing the transition of duplex DNA into topologically distinct functional nucleic acid structures. Our conclusion is that neither analog tested is a perfect reporter. Rather, we suggest the two should be used in conjunction to obtain an overall description of changes to nucleic acid structure. While $\mathrm{tC}^{\circ}$ has a very good quantum yield that allows for FDCD analysis, it exhibits only minor changes in fluorescence lifetime between ss- or dsDNA. PdC, on the other hand, undergoes a substantial decrease in the fluorescence lifetime when base-paired, but shows no FDCD signal at concentrations appropriate for most biochemical studies. Hence, we conclude that to map the transition of duplex DNA to other functional forms, both $\mathrm{PdC}$ and $\mathrm{tC}^{\circ}$ at concentrations up to $8.5 \mu \mathrm{M}$ can be used, depending on 


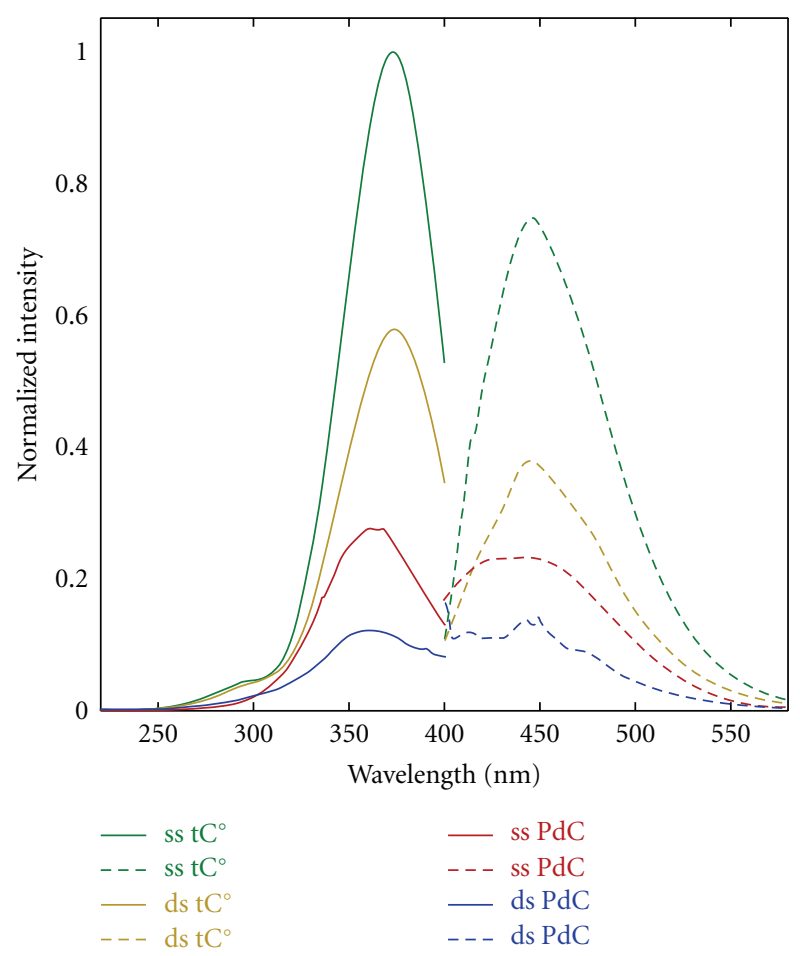

Figure 4: Excitation and emission spectra of $\mathrm{PdC}$ and $\mathrm{tC}^{\circ}$ incorporated in ss- and dsDNA. The solid and dotted curves stand for excitation and emission spectra, respectively. All samples were at $0.35 \mu \mathrm{M}$ concentration.

the structural information desired. We are now investigating spectral changes incurred by these probes, when they are contained within well-known functional DNA structures, such as quadruplex and i-motif DNA.

\section{Acknowledgment}

This paper has been supported by the US National Science Foundation EPSCoR Grant EPS-0903787.

\section{References}

[1] S. Burge, G. N. Parkinson, P. Hazel, A. K. Todd, and S. Neidle, "Quadruplex DNA: sequence, topology and structure," Nucleic Acids Research, vol. 34, no. 19, pp. 5402-5415, 2006.

[2] M. D. Frank-Kamenetskii and S. M. Mirkin, "Triplex DNA structures," Annual Review of Biochemistry, vol. 64, pp. 65-95, 1995.

[3] M. S. Han, A. K. R. Lytton-Jean, and C. A. Mirkin, "A gold nanoparticle based approach for screening triplex DNA binders," Journal of the American Chemical Society, vol. 128, no. 15, pp. 4954-4955, 2006.

[4] R. M. Wadkins, "Targeting DNA secondary structures," Current Medicinal Chemistry, vol. 7, no. 1, pp. 1-15, 2000.

[5] C. T. McMurray, "DNA secondary structure: a common and causative factor for expansion in human disease," Proceedings of the National Academy of Sciences of the United States of America, vol. 96, no. 5, pp. 1823-1825, 1999.
[6] H. J. Lipps and D. Rhodes, "G-quadruplex structures: in vivo evidence and function," Trends in Cell Biology, vol. 19, no. 8, pp. 414-422, 2009.

[7] H. Moore, P. W. Greenwell, C. P. Liu, N. Arnheim, and T. D. Petes, "Triplet repeats form secondary structures that escape DNA repair in yeast," Proceedings of the National Academy of Sciences of the United States of America, vol. 96, no. 4, pp. 15041509, 1999.

[8] M. Nambiar, G. Goldsmith, B. T. Moorthy et al., "Formation of a G-quadruplex at the BCL2 major breakpoint region of the $\mathrm{t}(14 ; 18)$ translocation in follicular lymphoma," Nucleic Acids Research, vol. 39, pp. 936-948, 2011.

[9] D. B. Davies, V. I. Pahomov, and A. N. Veselkov, "NMR determination of the conformational and drug binding properties of the DNA heptamer $\mathrm{d}(\mathrm{GpCpGpApApGpC)}$ in aqueous solution," Nucleic Acids Research, vol. 25, no. 22, pp. 45234531, 1997.

[10] W. Mäueler, G. Bassili, C. Epplen, H. G. Keyl, and J. T. Epplen, "Protein binding to simple repetitive sequences depends on DNA secondary structure(s)," Chromosome Research, vol. 7, no. 3, pp. 163-166, 1999.

[11] T. A. Brooks and L. H. Hurley, "Targeting MYC expression through G-quadruplexes," Genes Cancer, vol. 1, pp. 641-649, 2010.

[12] T. A. Brooks, S. Kendrick, and L. Hurley, "Making sense of G-quadruplex and i-motif functions in oncogene promoters," FEBS Journal, vol. 277, no. 17, pp. 3459-3469, 2010.

[13] M. Kimoto, T. Mitsui, S. Yokoyama, and I. Hirao, "A unique fluorescent base analogue for the expansion of the genetic alphabet," Journal of the American Chemical Society, vol. 132, no. 14, pp. 4988-4989, 2010.

[14] M. J. Rist and J. P. Marino, "Fluorescent nucleotide base analogs as probes of nucleic acid structure, dynamics and interactions," Current Organic Chemistry, vol. 6, no. 9, pp. 775-793, 2002.

[15] P. Sandin, L. M. Wilhelmsson, P. Lincoln, V. E. Powers, T. Brown, and B. Albinsson, "Fluorescent properties of DNA base analogue tC upon incorporation into DNA-negligible influence of neighbouring bases on fluorescence quantum yield," Nucleic Acids Research, vol. 33, no. 16, pp. 5019-5025, 2005.

[16] S. J. O. Hardman and K. C. Thompson, "Influence of base stacking and hydrogen bonding on the fluorescence of 2aminopurine and pyrrolocytosine in nucleic acids," Biochemistry, vol. 45, no. 30, pp. 9145-9155, 2006.

[17] X. Zhang and R. M. Wadkins, "DNA hairpins containing the cytidine analog pyrrolo-dC: structural, thermodynamic, and spectroscopic studies," Biophysical Journal, vol. 96, no. 5, pp. 1884-1891, 2009.

[18] S. Preus, K. Kilså, L. M. Wilhelmsson, and B. Albinsson, "Photophysical and structural properties of the fluorescent nucleobase analogues of the tricyclic cytosine (tC) family," Physical Chemistry Chemical Physics, vol. 12, no. 31, pp. 88818892, 2010.

[19] P. Sandin, K. Börjesson, H. Li et al., "Characterization and use of an unprecedentedly bright and structurally non-perturbing fluorescent DNA base analogue," Nucleic Acids Research, vol. 36, no. 1, pp. 157-167, 2008.

[20] L. M. Wilhelmsson, "Fluorescent nucleic acid base analogues," Quarterly Reviews of Biophysics, vol. 43, no. 2, pp. 159-183, 2010. 
[21] M. S. Z. Horwitz, "Transcription regulation in vitro by an E. coli promoter containing a DNA cruciform in the -35 region," Nucleic Acids Research, vol. 17, no. 14, pp. 5537-5545, 1989.

[22] D. M. J. Lilley, D. Chen, and R. P. Bowater, "DNA supercoiling and transcription: topological coupling of promoters," Quarterly Reviews of Biophysics, vol. 29, no. 3, pp. 203-225, 1996.

[23] N. P. Johnson, W. A. Baase, and P. H. von Hippel, "Low energy CD of RNA hairpin unveils a loop conformation required for $\lambda \mathrm{N}$ antitermination activity," Journal of Biological Chemistry, vol. 280, no. 37, pp. 32177-32183, 2005.

[24] D. Jose, K. Datta, N. P. Johnson, and P. H. von Hippel, "Spectroscopic studies of position-specific DNA "breathing" fluctuations at replication forks and primer-template junctions," Proceedings of the National Academy of Sciences of the United States of America, vol. 106, no. 11, pp. 4231-4236, 2009.

[25] J. Kypr, I. Kejnovská, D. Renčiuk, and M. Vorlíčková, "Circular dichroism and conformational polymorphism of DNA," Nucleic Acids Research, vol. 37, no. 6, pp. 1713-1725, 2009.

[26] N. P. Johnson, W. A. Baase, and P. H. von Hippel, "Investigating local conformations of double-stranded DNA by lowenergy circular dichroism of pyrrolo-cytosine," Proceedings of the National Academy of Sciences of the United States of America, vol. 102, no. 20, pp. 7169-7173, 2005. 

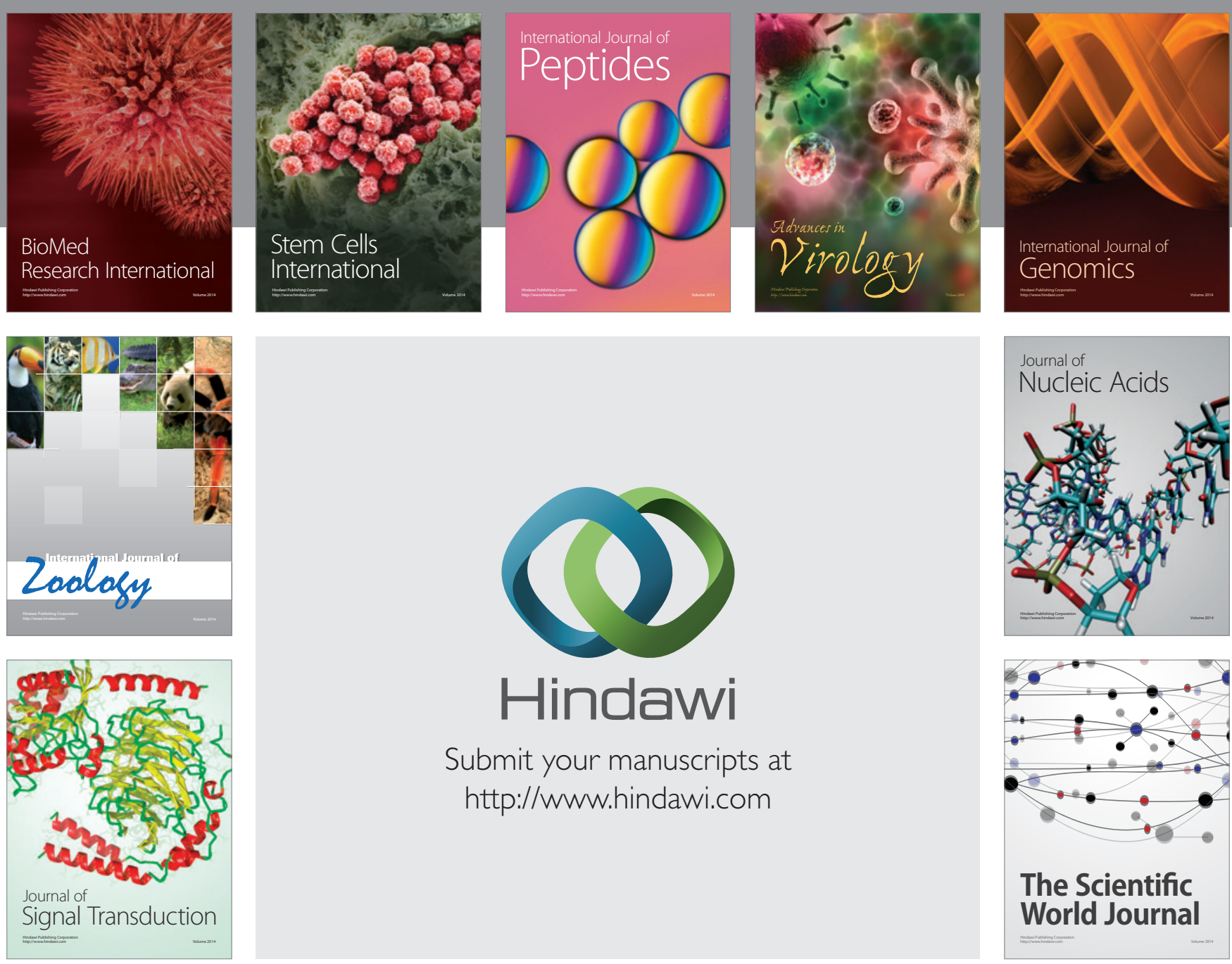

Submit your manuscripts at

http://www.hindawi.com
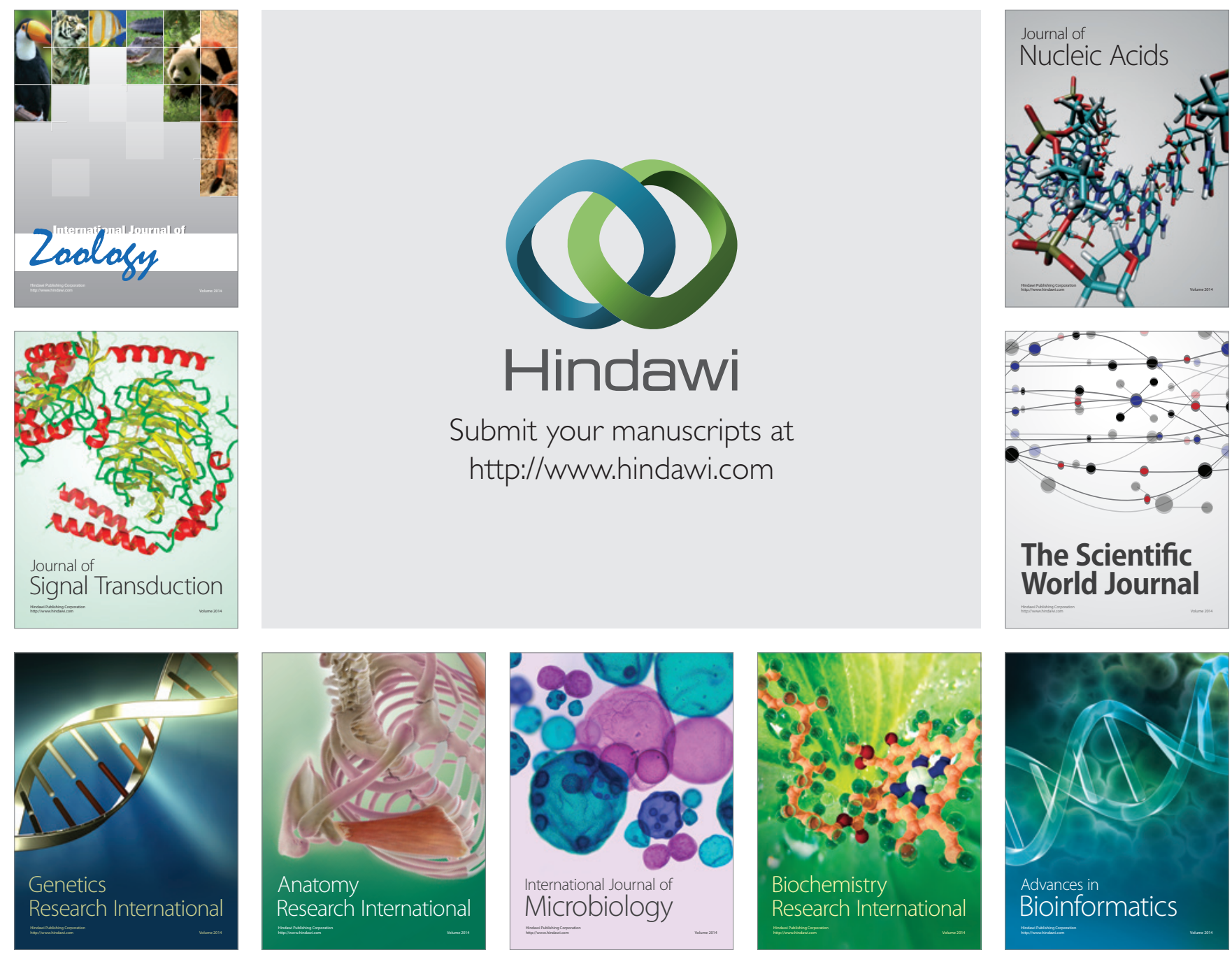

The Scientific World Journal
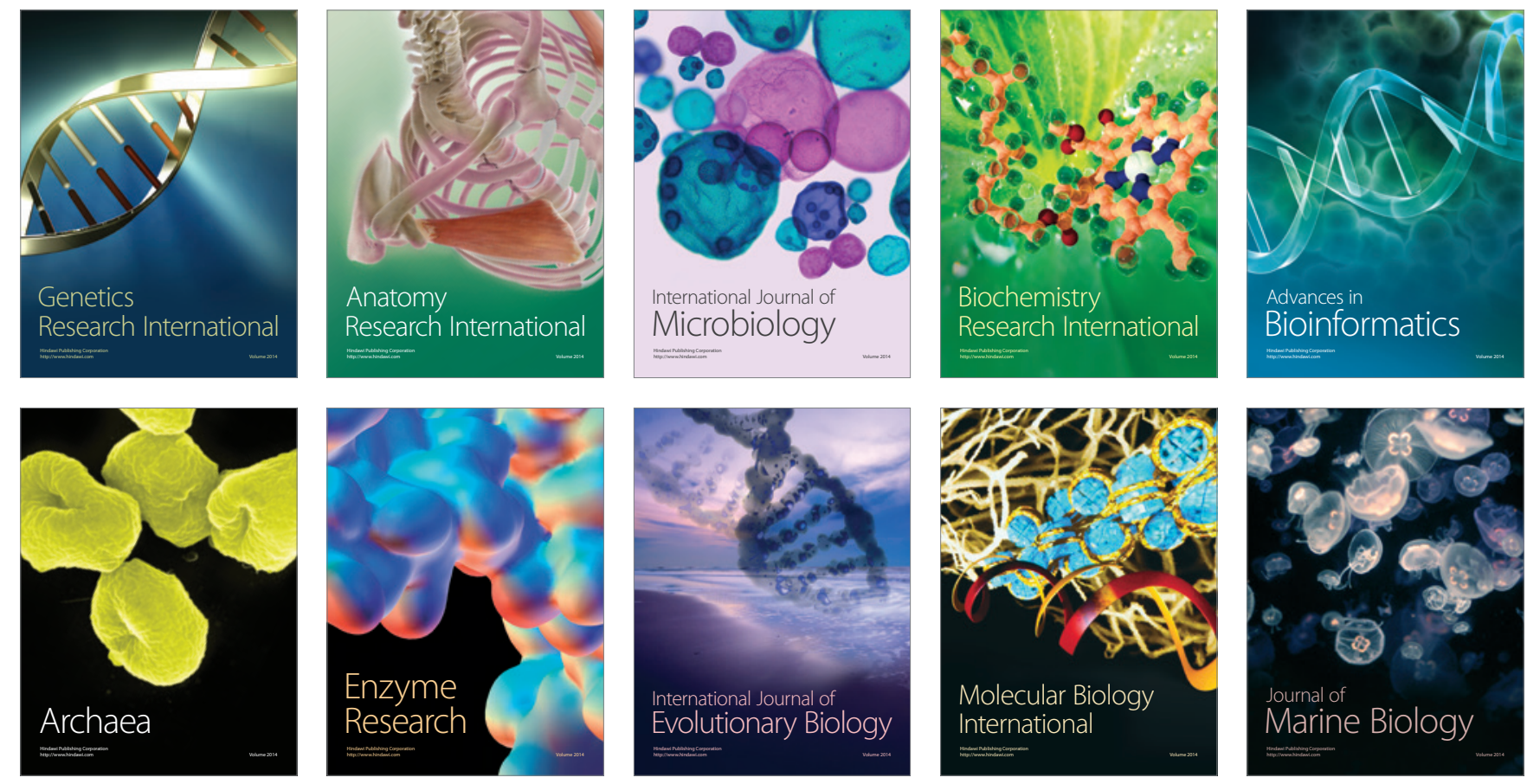